\title{
A Conceptual Framework for Vulnerability Assessment of Climate Change Impact on Critical Oil and Gas Infrastructure in the Niger Delta
}

\author{
Justin Udie *, Subhes Bhattacharyya ${ }^{(1)}$ and Leticia Ozawa-Meida \\ Institute of Energy and Sustainable Development, Faculty of Technology, De Montfort University, the Gateways, \\ Leicester LE1 9BH, UK; subhesb@dmu.ac.uk (S.B.); lozawa-meida@dmu.ac.uk (L.O.-M.) \\ * Correspondence: Justyno27@gmail.com; Tel.: +44-(0)-741-358-2757
}

Received: 26 October 2017; Accepted: 4 February 2018; Published: 12 February 2018

\begin{abstract}
The impact of climate change on the Niger Delta is severe, as extreme weather events have inflicted various degrees of stress on critical oil/gas infrastructure. Typically, assets managers and government agencies lack a clear framework for evaluating the vulnerability of these systems. This paper presents a participatory framework for the vulnerability assessment of critical oil/gas infrastructure to climate change impacts in the Niger Delta context. Through a critical review of relevant literature and triangulating observational and exploratory data from the field, this paper has developed a conceptual framework with three elements: (1) a preliminary scoping activity; (2) the vulnerability assessment; and (3) mainstreaming the results into institutional asset management codes. Scoping involves the definition of research aims and objectives, review of prevailing climate burdens and impacts, exploratory investigation, screening for new (planned) assets and selection of relevant infrastructure. The emphasis on screening for planned infrastructure is to facilitate the incorporation of sustainable adaptive capacities into the original design of identified systems. A conceptual framework for vulnerability assessment is presented as a robust systematic iterative model for the evaluation of selected assets using an appropriate methodology. In this study, analytic hierarchy process (AHP) is applied while mainstreaming as part of the research framework is emphasised to aid commercial implementation from an expert-based perspective. The study recommends the use of other suitable methodologies and systematic approaches to test the flexibility of the framework.
\end{abstract}

Keywords: conceptual framework; vulnerability assessment; climate change; Niger Delta

\section{Introduction}

Climate change constitutes one of the greatest contemporary environmental menaces impacting the oil and gas industry in the Niger Delta. Extreme weather events, such as rising temperature, Atlantic tides and thermal expansion of the ocean, lead to frequent heavy downpours, increased frequency of storms and regular occurrences of flood, which severely affect critical oil and gas infrastructure [1-3]. These events have placed enormous burdens on infrastructure, hindering adaptation strategies and causing an overall negative impact on the Nigerian oil dependent economy [3,4]. The Nigerian economy relies on the functioning of upstream, midstream and downstream sectors of the oil/gas value chain (Figure 1) for its survival as crude oil revenue constitutes about $75 \%$ of foreign export earning of the country. The vulnerability of infrastructure due to extreme weather events implies a high risk to the economy, environment and social systems. More so, the inter-linkages between the infrastructure across streams demonstrate the severity of threats as the impact on assets in the downstream has the capacity to trigger cascading effect on the upstream and midstream sectors of the industry. 


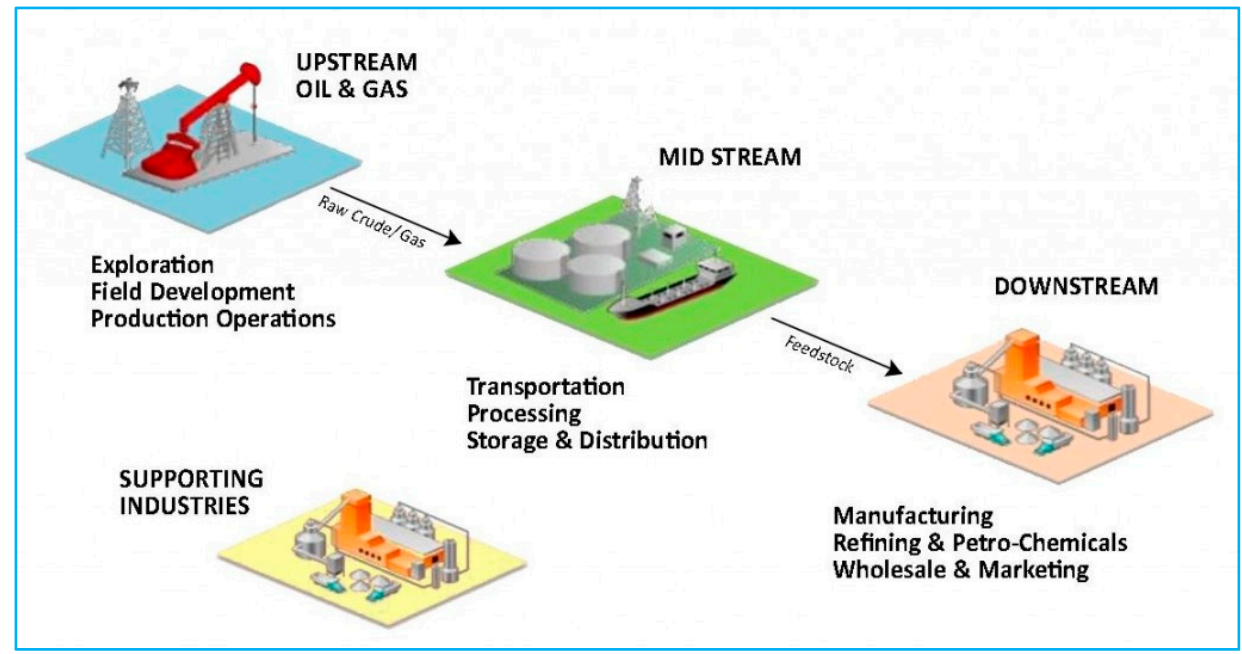

Figure 1. Global oil/gas sector value chain. Source: [5].

However, about $80 \%$ of government's revenue is generated from fossil energy resources. The production in the Niger Delta provides energy supplies to Western Africa and to most other economies across the world [6,7]. Oil/gas industry contributes to the local economy by providing an enabling environment for the hospitality industry, supporting local commerce through educational services provision and developing contractual partnerships and other corporate social services within the region. Prevailing extreme climate events show that activities related to the oil and gas business in the region are being subjected to unprecedented environmental and economic crisis. The impacts are aggravated by a complete absence of a clear industry-focused conceptual framework for the assessment of vulnerability. Such assessment underpins the intensity and effects of extreme climatic events on all critical infrastructure [8]. This study demonstrates the assessment of climate change vulnerability of oil and gas industry using a pragmatic framework with the involvement of stratified stakeholders from the industry.

Climate impact assessment paves the way for a timely identification of risks and estimation of impact severity. Assessing climate vulnerability through the application of a multi-stakeholder approach leads to the identification of sustainable adaptation strategies that could significantly improve infrastructure resilience [9]. It is being argued that impacts forced by extreme weather events in the Niger Delta are partly due to low awareness and understanding of climate related risks magnitude. Our conceptual framework provides a systematic evaluation that is intrinsically designed for the climate investigation of oil and gas critical infrastructure [8,10].

Despite climate burdens are uncertain and not fully predictable, it is believed that continued gas flaring in the Niger Delta and increasing local fossil energy consumption would further exacerbate global warming effects causing more regular flood activities in the region. Implications are that infrastructure could be more vulnerable throughout the 21st century [11,12]. Existing frameworks for vulnerability assessment focus on policy choice, adaptation planning and ecosystem management emphasis on established systems. However, apparent exclusion of new or developing systems can lead to premature exposure and subsequently increase the vulnerability of the region. Hence, what inclusive framework could aid the assessment of prevailing climate burdens and vulnerability of both established and planned critical assets? Could planned (new) assets be vulnerable? What methodological approach could be applicable in the assessment process?

This paper presents a conceptual framework for vulnerability assessment of critical oil/gas assets that emphasises the scoping of prevailing climate burdens and evaluation of their impact levels on both existing and emerging oil/gas infrastructure in a hierarchical order. Multi-criteria decision-making processes have been used in vulnerability assessments previously [13]. In this paper, 
the analytic hierarchy process (AHP) is suggested as a useful methodology for participatory ranking of infrastructure based on their vulnerability using multiple stakeholders and multiple attribute system. Stakeholder inputs through a participatory process make AHP application valuable for such an analysis.

The purpose of this paper is to provide a flexible and focused assessment tool for vulnerability assessment in the oil and gas industry in the context of the Niger Delta. The aim is to support management of critical energy assets subject to extreme climate effects. Following this introduction that provides a brief background of the study, Section 2 reviews relevant literature and academic theories and identifying the gaps associated with the existing frameworks with the view to draw up a specific framework for the oil and gas industry. Section 3 briefly examines the application of AHP to strengthen the framework, while Sections 4 and 5 present the analysis of framework principles, recommendation and conclusions.

\section{Review of Applicable Frameworks}

The effectiveness of a research framework depends on its empirical application process, the flexibility of content structure and tangible outputs [14,15] It also relies on its ability to fit into academic theories and present an interpretable picture for commercial and industrial application [16]. In the context of climate change vulnerability assessment, academics and experts have engaged in a global request to understand available knowledge for critical infrastructure protection. This has created interdisciplinary approaches that seek to integrate expert and academic viewpoints in assessing the vulnerability to climate through an acceptable and applicable framework.

\subsection{Climate Change Vulnerability Assessment}

Studies indicate that conventional environmental impact assessment (EIA) seems to dominate the environmental sector but emerging climate extreme events tend to nullify the substitution of an EIA for climate impact assessment [17-19]. Since EIA fails to capture the impact of the environment on assets, the vulnerability assessment of critical infrastructure to flood, storms and increasing temperature is significantly undermined. Hence, the concept of vulnerability assessment has become more relevant to the industry in recent times. This is because while EIA focuses on the impact of business on the environment (sewage disposal, deforestation, contamination and impact on humans), vulnerability assessment focuses on the environmental impact on businesses (the oil/gas industry). Vulnerability assessment allows managers and businesses to invest in adaptation plans against extreme climate events such as sea level rise (SLR) and flooding. SLR impacts coastal areas and associated infrastructure including commerce, telecom, transport (roads, railways and bridges) and energy installations [20]. In the coastal Niger Delta oil/gas industry, there is no defined framework for assessing the vulnerability of its coast. In South Wales, a coastal vulnerability framework based on the observation of physical parameters was used to assess the vulnerability of Loughor estuary instead of an expert multi-stakeholder approach. The investigation found that width of beaches and coastal slope contribute significantly towards vulnerability [21]. While physical attributes of a framework influence the result of climate vulnerability assessment, Oh, E.H. et al. [22] consider that an assessment framework involving associated industries and communities could be more engaging and beneficial if it involves relevant stakeholders.

Assessment of climate vulnerability encompasses various stakeholders; industries, communities, government environmental regulators and the academia. Previous research on vulnerability frameworks focused on climate mitigation, adaptation, ecosystems management, energy demand, storage and policy development [8,23-25]. The focus of these approaches is limited to contributions of the assessment process to policy development while interdisciplinary analysis of critical infrastructure (majorly oil/gas) is missed. Other frameworks concentrate on assessment of various environmental concepts such as desertification, urbanisation and adaptation barriers $[8,16,25,26]$ This continue to negate the inclusion of vulnerable critical systems in assessment from multi-stakeholder perspective. 
A framework for the assessment of critical oil/gas infrastructure (capturing new or planned infrastructure) is lacking in the Niger Delta case. There is a need for a robust integrated multi-stakeholder conceptual framework for inclusive infrastructure vulnerability assessment in the context of the oil and gas industry.

\subsection{Vulnerability Assessment of Critical Infrastructure}

Experts in the industry provide a short-term non-inclusive framework for vulnerability assessment that often discriminates new infrastructure from being assessed. This phenomenon requires continuous investigation, which is often time consuming and capital intensive. An inclusive research framework that technically provides a theoretical concept for a holistic assessment could be more appreciated in empirical instances. The following paragraphs discuss expert based frameworks developed by the Washington Department of Transport (WSDOT), the US Federal Highway Administration [27], the Australian Capital Territory [14] and the Science Applications International Corporation [28] to investigate climate and other related risks impact on 'existing' critical infrastructure.

The Washington Department of Transport (WSDOT) developed a framework for assessing climate change impact on transport infrastructure [29]. Essentially, the framework has a three-way approach-scoping, assessment and decision-making stages but only for transport systems. The framework focused on "owned transport infrastructure" and ignores other roads and associated infrastructure belonging to other organisations or departments. This could be to avoid bureaucracies associated with ethical and accreditation challenges in dealing with external assets. This however implies that planned infrastructures were left at the risk of climate change impact. Sea ports, energy and marine transport systems, were not assessed. The method of analysis (expert's judgement) could not validate the result and justify the research process. Discriminating factor associated with this framework is its lack of flexibility and transferability. It does not seem to allow interdisciplinary inputs, making it less effective for interdisciplinary application such as in the Niger Delta case. It also fails to capture the ability of incorporating developing assets. Fuchs et al. [30] argued that contemporary assessment must be inclusive and comprehensive, incorporating designing, planning, building and new assets management.

The US Federal Highway Administration (FHWA) infrastructure assessment pilot team designed a framework, which focuses more on collecting data on existing assets and climate data for assessment. About one hundred and fifty (150) infrastructures were gathered for vulnerability assessment [27]. The sample size of assets scoped for assessment has been criticised by academics arguing that it could be cumbersome, time consuming and capital intensive [31]. The implication of time, on climate related assessment could invalidate the research aim and objectives due to environmental changes and uncertainties in the climate change case. To minimise uncertainties, FHWA organised workshops and used a qualitative "combination and elimination" approach to shortlist assets and eliminate those that are less likely to be vulnerable. This approach is not efficient in selecting and prioritising assets; it may allow irrelevant or less vulnerable systems to be shortlisted while the most vulnerable ones are excluded. This combination and elimination selection method can hinder stakeholder's independent judgement and arbitrary exclusion of infrastructures (based on individual priorities) could miss most critical systems [32]. Although numerous assets were initially selected, the framework yet failed to consider the existence of developing infrastructure. This implies that a different assessment is required for developing assets, which could amount to extra cost for organisations.

The Australian Capital Territory (ACT) developed a framework for climate impact and vulnerability assessment [14]. The framework focused primarily on policies associated with disaster risk management for infrastructure rather than exposure of assets to physical environmental threats. The main components of the framework evaluate existing and new systems based on available policies that include agenda setting, planning, analysis and delivery. This framework presents a policy evaluation approach where each section requires a separate research design and strategy. This makes it complicated and less easy to replicate in other sectors by experts who are not familiar with the 
approach. The use of multiple methodologies further complicates the framework and restricts its application only to ACT stakeholders and researchers. Though the framework uses a stakeholder approach in the selection of new infrastructure for assessment [14], the selection process is loose and it does not allow mainstreaming findings. These limitations hinder knowledge sharing, dissemination of information and awareness creation among stakeholders. Saaty [13] contended that unguided systematic stakeholder participation may introduce bias and supremacy of opinions that may attenuate the rigour of selecting most vulnerable systems, which may affect the validity of the entire process and the result. Nevertheless, engaging stakeholders in vulnerability assessment reduces the financial burden and further captures government's attention, establishing knowledge sharing, technology transfer and policy making perspectives. However, the ACT approach is inclusive of developing (new) infrastructure, which is a fairer strategy that could suggest effective incorporation of adaptation approaches from construction and installation stages. Fussel $[33,34]$ argued concurrently that the inclusion of developing infrastructure in climate vulnerability assessment is novel, because it can mitigate long term risks and can allow for adequate inherent adaptation planning.

Finally, the Science Application International Corporation (SAIC) designed an experts based framework for the assessment of vulnerable highways to terror attacks [28]. SAIC provides a comprehensive guide (including stochastic models) for assessing critical infrastructure such as bridges, roads, tunnels, gas pipelines, etc. However, how this framework could fit into the assessment of critical oil/gas infrastructure (as in the case of Niger Delta context) and form a substantial part of assets assessment portfolio is not known. The safety, maintenance and operations of oil/gas facilities are participatory in general-involving expert communities, industrial practitioners and government regulatory entities. Vulnerability of oil/gas infrastructure to extreme climate events forced by climate change has a cascading impact on all stakeholders in the assets management value chain. An inclusive conceptual framework for vulnerability assessment from scoping to mainstreaming in a concise pathway including relevant stakeholders could suffice efficient adaptation planning.

Nevertheless, a framework, which accommodates stakeholders' participation and allows for institutionalisation in the industry through an acceptable methodology could win expert, non-expert and academic support. The combination of this framework with an appropriate assessment methodology could reduce routine maintenance cost, implication of time and minimise major future impacts on planned systems. In this study, a participatory methodology is briefly explained to aid an understanding of the framework concept.

\section{Methodology}

This study examines approaches of framework design for assessing vulnerability of critical infrastructure through; (a) an intensive review of vulnerability assessment frameworks in relevant academic literature available. It also consults expert reports and publications from reputable organisations as discussed in Section 2; (b) exploratory and observational field investigation of infrastructure vulnerability conducted in the Niger Delta oil/gas industry in 2016; and (c) analysis of documentary data sets that effectively triangulate the research process.

Four multinational corporations were selected for investigation of their assets' vulnerability. Using a multi-stakeholder approach, experts and field engineers with at least ten years of regional operational experience were contacted and stratified into four focus groups. These groups were engaged in a participatory assessment processes by administration of specialised analytic hierarchy process (AHP) questionnaires (further explained in the next section). Confidentiality agreements were signed with each company while each participant also signed a participants' consent form in fulfilment of ethical and data protection requirements. A brief explanation of the procedure for completing AHP questionnaire was provided through illustration on a flipchart. A thorough description of participatory pairwise comparison of multiple alternatives for ranking selected assets in order of vulnerability was given. The results were analysed by using a multiple input (Mi-AHP) spreadsheet developed by Goepel [32]. Details of analysis and corresponding results are not presented in this paper, as these 
are outside its scope. The aim of this paper is to present a conceptual framework (pathway) for vulnerability assessment using AHP approach among other multi-criteria decision-making approaches. Although different methodologies could be suitably integrated into the framework to achieve similar aim and objectives, a brief insight of the application of AHP is provided as a guide to support its selection for this study.

\section{Analytic Hierarchy Process (AHP)}

The review of relevant literature and empirical investigation suggests that a three-phase activity framework pathway suffices the smooth assessment of climate impact on vulnerable critical oil/gas infrastructure in the Niger Delta. In this study, the analytic hierarchy process (AHP) was used to prioritise infrastructure for vulnerability assessment using climate sustainability-based indicators such as exposure, adaptive capacity, criticality of assets, proximity, interdependence, presence of climate burdens and obsolescence. AHP is a model developed and used for hierarchical multi-criteria decision-making analysis involving multiple alternatives [35-37]. AHP was considered for this investigation because it is suitable for participatory research. It is suitable for multi-stakeholder decision-making process involving multiple alternatives. A scale of 3 (moderate importance), 5 (strong importance), 7 (very strong important), 9 (extreme importance) (Table 1) [35] was adopted for pairwise ranking. AHP Metric systems also allows the incorporation of climate change elements into the assessment framework by comparing climate indicators (criteria) with the selected infrastructure (alternatives) to determine vulnerability.

Table 1. Saaty Analytic Hierarchy Process (AHP) numerical scale.

\begin{tabular}{cc}
\hline Numerical Scale & Verbal Scale (Interpretation) \\
\hline 1 & Equal importance $(i=j)$ \\
3 & Moderate importance $(i$ is lightly important than $j)$ \\
7 & Strong importance $(i$ is strongly important than $j)$ \\
9 & Very strong importance $(i$ is very strongly important than $j)$ \\
$2,4,6,8$ & Extreme importance $(i$ is extremely important than $j)$ \\
\hline
\end{tabular}

This paper presents a combined use of specialised AHP questionnaire and focus group approaches for data collection. Interdisciplinary participants in focus groups were carefully stratified and selected based on career niche (mainly environmental managers and assets evaluators) and experience (at least ten years of practice in the industry). Analytic hierarchy process involves a three-level pathway (Figure 2):

(a) Determination of the assessment goal. In this study, the goal (aim) of assessment is to determine the vulnerability of critical oil/gas infrastructure to climate change impacts in the Niger Delta.

(b) Composition and decomposition of attributes (criteria). This involves further breakdown of criteria (attributes) where possible. The criteria developed for assessment of vulnerability in this study include exposure and proximity to climate burdens, age (obsolescence), adaptive capacity, criticality, presence of burdens and interdependence of systems. The decomposed criteria reduce ambiguity and ensure that both tangible and intangible associated measures are synthesised in each criterion.

(c) Prioritisation of alternatives (wellheads, pipelines, flow stations, terminals, loading bays, roads and bridges, transformers/high voltage cables) The criteria are used to pairwise compare shortlisted infrastructure in terms of vulnerability to determine hierarchies of vulnerability. 


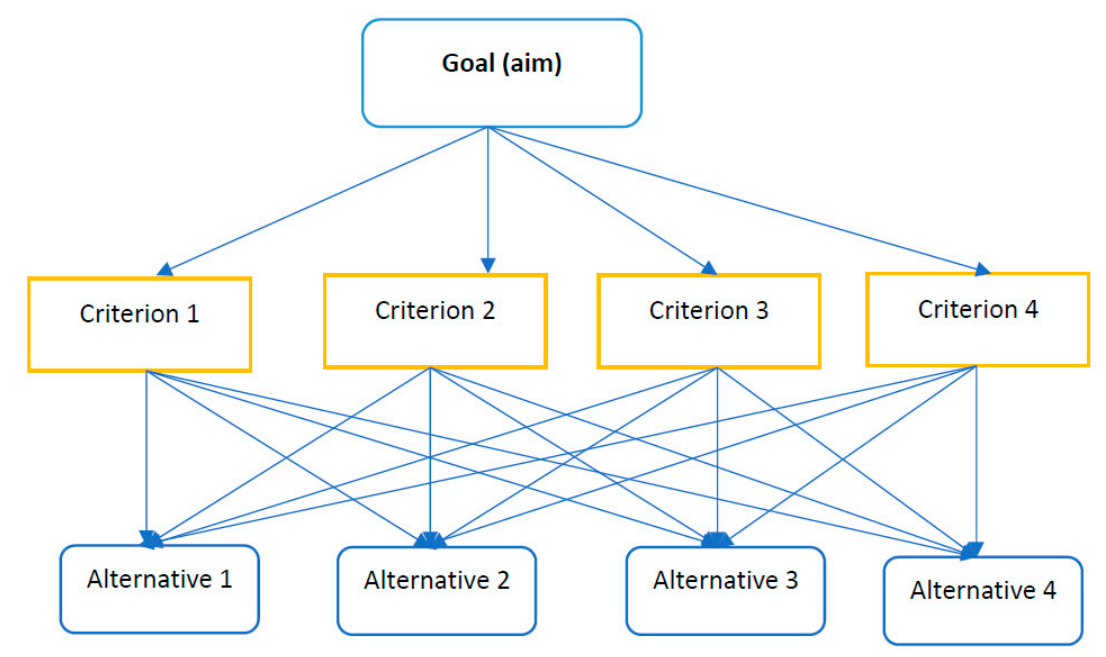

Figure 2. Schematic representation of three phase of AHP comparison pathway.

As illustrated in Figure 2, the comparison is a systematic pairwise process that follows a matrix system. This was completed by participants that completed the specialised AHP questionnaire. Pairwise comparison matrix is illustrated below:

$$
\mathbf{A}=\left|\begin{array}{lll}
a_{11} & a_{12} & a_{13 \ldots n} \\
a_{21} & a_{22} & a_{23 \ldots n} \\
a_{n 1} & a_{n 2} & a_{n 3 \ldots n} \ldots
\end{array}\right|
$$

where if $a_{i j}=1, a_{j i}=1 / a_{i j}$ (example; if $\left.a_{13}=5, a_{n 1}=1 / 5\right) ; a_{i i}=1 ; i$ and $j$ are equally important, $a_{i j}=a_{j i}=1$

A brief description of AHP is provided to signpost readers to a suitable methodology used in line with the framework to achieve the overall aim. More details of stepwise procedure of application of AHP in previous vulnerability assessment studies are available from [13,38,39].

Based on the review of literature, observations and exploratory research, a framework is conceptualised with the application of AHP.

\section{Framework Development Process}

This section describes the three elements and embedded sub-elements of the framework, from scoping through iterated vulnerability assessment to mainstreaming, as they were applied in the Niger Delta case.

\subsection{Scoping Processes}

Scoping involves the careful review of relevant literature to determine the research aim and objectives, exploration and identification of climate burdens and relevant infrastructure in the study area. It further involves setting the hypothesis of study and screening for new (planned) infrastructure that could be vulnerable to climate change impacts [40]. It also provides a scalable time for review of assets sensitivity, vulnerability, adaptive capacities and delineation of infrastructure deemed vulnerable and critical [41]. Scoping provides an understanding of a broad view of the climate situation (risks) and impacts in the study area for detecting signals of past extreme weather events as they have affected infrastructure [42]. Direct and indirect potential effects that constitute future risks are studied at the scoping stage. Scoping dimension adds up to the uniqueness of a research framework as it captures all elements of assessment and reduces the risks of future vulnerabilities. This is because embedded adaptive capacities against future climate risks could be considered from building and fabrication stage of planned assets $[15,43,44]$. 


\subsubsection{Determination of Research Aim and Objectives}

Identification of critical oil and gas infrastructure was conducted through desk process literature review, while the exploration of the research area through field investigation. The aim was to conduct a vulnerability assessment of these critical infrastructure in the Niger Delta with the major objective of promoting sustainable adaptation planning process for most vulnerable systems. It was discovered from field survey that prevailing climate burdens in the region include sea level rise (SLR), surging Atlantic tides, frequent heavy downpour, rising temperature, impact of saline water and frequent tropical storms. These burdens have a history of causing regular flood disasters, corrosion of cathodic systems and deactivation of temperature dependent systems such as the flow stations, among others [45].

\subsubsection{Exploratory Investigation}

For operational scoping of oil/gas assets six months of exploratory field investigation was conducted to identify prevailing climate change burdens, historical impacts and shortlist assets that could be vulnerable in the study area. Seven infrastructures were shortlisted through a pre-assessment interview with stakeholders previously mentioned in four oil companies. Based on expert's perspectives, systems were selected based on those assets that are frequently operational in the mainstream day-to-day production, processing and transportation of crude products and that could be particularly vulnerable to climate induced extreme weather impact. These include: pipelines (trunk lines), oil wellheads, flow stations, terminals, roads/bridges, transformers and high voltage cables and loading bays.

\subsubsection{Screening for New (Planned) Infrastructure}

A separate dimension to the screening and inclusion of planned infrastructure at the start of this framework is to eliminate obvious exposure and avoid future repetition of assessments process and save time, energy, cost and reduces the risks of predicted impacts. It places assets on a long-term operational sustainability, making it efficient and effective for an extended period without being vulnerable to extreme climatic factors. The proposed framework considers uncertainties associated with climate change and environmental disasters. A cost benefit analysis is undertaken to ensure that incorporated adaptation mechanisms are effective, cost-effective and flexible [46,47]. This in-depth assessment is referred to by some environmental authors as screening analysis [48,49] involving a critical assessment of adaptation plans, monitoring and evaluation of environmental strategies.

In this study, the screening strategy led to the identification of a crucial gas system-central compressed processing and central processing facility (CCP/CPF) plant. The CCP/CPF is in Yokiri Forcados Integrated Power (FYIP) project portfolio, North Bank Flow Station (NBFS) see Figure 3. The function of CCP/CPF is to monetise associated gas from an oil reservoir through compression for export and to meet domestic gas demand [50]. Further screening revealed that the facility is being constructed on inundated natural ground just 3.0-4.5 m above sea level at a distance less than $100 \mathrm{~m}$ to the Atlantic shore. These indicators show that the CCP/CPF is vulnerable to flooding, storms, temperature and wind impact from the design stage. In addition to its vulnerable location, the CCP/CPF has appendages such as compressor screws, reciprocating compressors, Joule-Thompson low temperature separation (JT-LTS) and slug catchers, that is highly sensitive to temperature for optimal operations [51]. This implies that the CCP/CPF is vulnerable to several factors that require consideration by the project contractor for sustainable and lasting operation. 


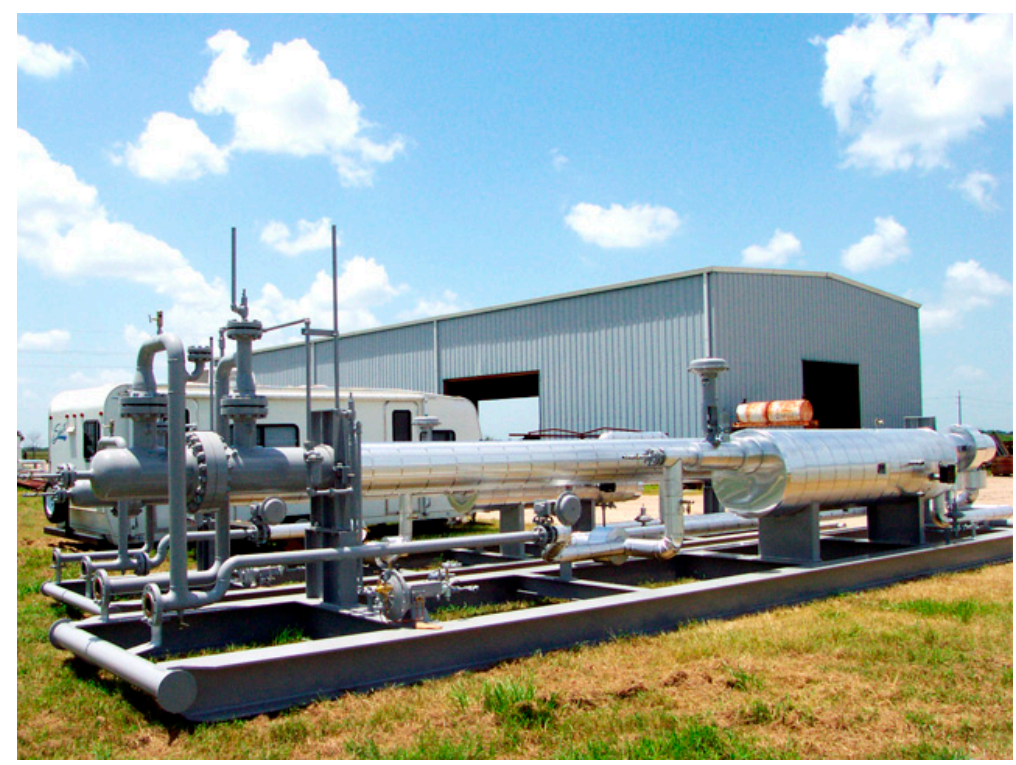

Figure 3. Typical Joule-Thompson low temperature separation (JT-LTS) facility installed in the Yokiri Forcados Integrated Power (FYIP) North Bank Flow Station, Ogulagha Island, Niger Delta. Source: [52].

\subsection{Vulnerability Assessment}

This is a major focus of the research framework. It involves a systematic iterative procedure of data collection and analysis using an appropriate methodology. Some authors consider conducting a pilot study as the first approach to vulnerability investigation [53,54] to ascertain the effectiveness of research methodology. In this study, the need for a pilot study in the scoping stage was replaced by an extensive review of literature and intensive exploration of the study area. The pathways discussed below describe how the vulnerability assessment was conducted:

\subsubsection{Stratification of Participants7}

Participants (decision-makers) identified in Section 4.1 were carefully stratified into four randomly mixed focus groups in a ratio of 5:5:5:4; making a total of nineteen participants. The need for the mixed group was due to their homogenous industrial experience, which indicates that there would not be any significant differences in their judgements. The group sizes were constituted for easy management and to allow for equal participation and fare dialogue between decision-makers. Equal participation provided an opportunity for eliciting qualitative data from follow-up discussions in the process of completing the AHP questionnaire. Moreover, Kitzinger [55,56] contended that the size of focus group participants can vary between five and eight while Dong et al. argued that groups of five (5) to seven (7) participants are acceptable when using AHP for decision-making [57].

\subsubsection{Introduction of Research Instruments}

Information sheets were distributed to each participant to introduce the data collection process. The research scope (aim, objective, rational) and methodology (see Section 3) were adequately explained to participants through a brief question and answer session. The process of navigating through the AHP questionnaire was satisfactorily demonstrated and understood by decision-makers.

\subsubsection{Application of AHP in Vulnerability Assessment}

Previous authors have employed the AHP in qualitative data collection process $[13,36,38]$ for solving different complex problems $[14,15,41]$. In this study, AHP is used to collect both quantitative and qualitative data simultaneously for vulnerability assessment involving multiple stakeholders. 
An audio recorder was used to record participants' verbal dialogues and transcribed as separate qualitative data set. Activities explained in Sections 4.2.1 and 4.2.2 were repeated in the four groups.

\subsubsection{Conduct Observational Field Assessment}

A vulnerability assessment observation approach differs from the scoping exploration conducted in Section 4.1.2. Observational data collection as used by Grove and Fisk [58] is introduced in the framework for empirical examination of infrastructure in their operational locations. The aim is to observe and record relevant effects and potential impacts of climate induced extreme event on selected infrastructure. Aside from the use of specialised questionnaires and focus group interviews, vulnerability assessment also involves the collection of secondary data [20]. In this study, documentary evidence on historical events such as flood impact, hydrogeological records and possible active flood responses available in the Niger was collected through field assessment. This observational assessment provided insights of some existing adaptation strategies in place such as ground water monitoring wells and water discharge rate monitoring models. These systems provide hourly signals on ground water behaviour and the rate of water discharged after the confluence of major water bodies such as the River Niger and Benue.

\subsubsection{Results Analyses (Using Appropriate Analytical Tools)}

The analysis of results is a critical element of the research framework. In this study, quantitative, qualitative and documentary data sets were collected through focus groups, participants' discussions, AHP questionnaire responses and field observational assessment. The focus group AHP data was analysed using [32] Goepel's multiple inputs (Mi-AHP) spreadsheet [39]. Audio data sets were transcribed and relevant content was extracted. Questionnaire and qualitative data were examined and triangulated to substantiate and validate the study process $[59,60]$. Application of AHP in participatory data collection and analysis eliminates the bias feared by Kloprogge and Van Der Slujis [61]. Findings are compared with existing literature and academic theories to ensure that identified research gaps, aim and objectives are addressed. However, if a different method is considered, analysis of result needs to synchronise with modalities of the chosen methodology [62,63] which may present results differently.

\subsubsection{Consider Mainstreaming the Process}

The lack of a conceptual framework for vulnerability assessment of climate change impacts in the Niger Delta was identified as a research gap. The successful and efficient application of the proposed framework in identification and assessment of vulnerable infrastructure is a contribution that filled this gap. This framework is therefore suggested to be mainstreamed into the asset management practices of the oil/gas industry with policy support. Details of mainstreaming are considered in the next section.

\subsection{Framework Mainstreaming}

The incorporation of the framework into the asset management and policy evaluation of oil/gas industry provides a practical instrument for routine vulnerability assessment. It is hoped that this instrument is supported with a policy backing by stakeholders to compel other practitioners, contractors and experts in relevant industries to implement vulnerability assessment strategies. Important characteristics of the proposed framework that justifies its mainstreaming include the incorporation of existing and new (planned) infrastructure through succinct scoping and effective hybridisation of participatory multi-criteria decision-making approach. The overall process demonstrates its flexibility and suitability across sectors addressing relevant aspects of effective adaptation strategies illustrated in Figure 4 and explained in Sections 4.1.1-4.1.3. 


\section{Framework mainstreaming}

a) Incorporate into infrastructure management policy (for emergency planning and disaster risk management, contribute to long-term adaptation planning and project prioritisation).

b) Awareness creation (bridging the knowledge gap, building public confidence and create investment opportunities)

c) Review, monitor progress, evaluate, implement and re-scope

Figure 4. Mainstreaming vulnerability assessment into policy making system.

\subsubsection{Infrastructure Management Policy}

An assessment framework policy could sustain emergency planning for critical infrastructure and enable disaster forecast and management procedure that could sustain the industry. The framework contributes to long-term adaptation planning as well as prioritisation of projects. For instance, it has been contended the most vulnerable infrastructures exist in the least developing countries due to location and lack of adaptation capacities [64]. Adaptation to climate induced extreme weather events in these countries and regions has become crucial. Policy makers, environmental regulatory agencies and concerned stakeholders require a framework for vulnerability assessment and prioritisation of adaptation strategies and disaster response planning.

\subsubsection{Awareness Creation}

Creating awareness and strengthening knowledge and capabilities are crucial performance indicators in contemporary infrastructure integrity management programmes. Mainstreaming the framework aids information dissemination and increases structural awareness in the oil and gas industry through multi-stakeholder participation. Awareness creation is fundamental to policy makers and stakeholders in the asset management process including government agencies. The framework is an on-demand tool that could be used to acquire trusted data of functional knowledge required to deal with and solve problems associated with infrastructure damage such as corrosion. It facilitates knowledge sharing through interdisciplinary interactions and participatory processes that bridge the gap in interdepartmental communication between stakeholders [65]. Mainstreaming the vulnerability assessment framework can build public trust and confidence, create investment opportunities facilitate access to credit institutions and lower insurance premiums for oil/gas companies [66,67].

\subsubsection{Review and Re-Scope}

Due to uncertainties associated with climate change forecast, the continual review of the assessment process is important. Infrastructure obsolescence and advancement in technology could trigger the review of the vulnerability assessment framework. The purpose of an iterative design of the framework is to provide the support for continual review of implementation strategies and determination of areas of improvement. The framework application process can be monitored, evaluated, reviewed and adjusted to allow for formulation of new research aim and objectives. These are incorporated into the overall vulnerability assessment framework (see Figure 5) for continual improvement. 


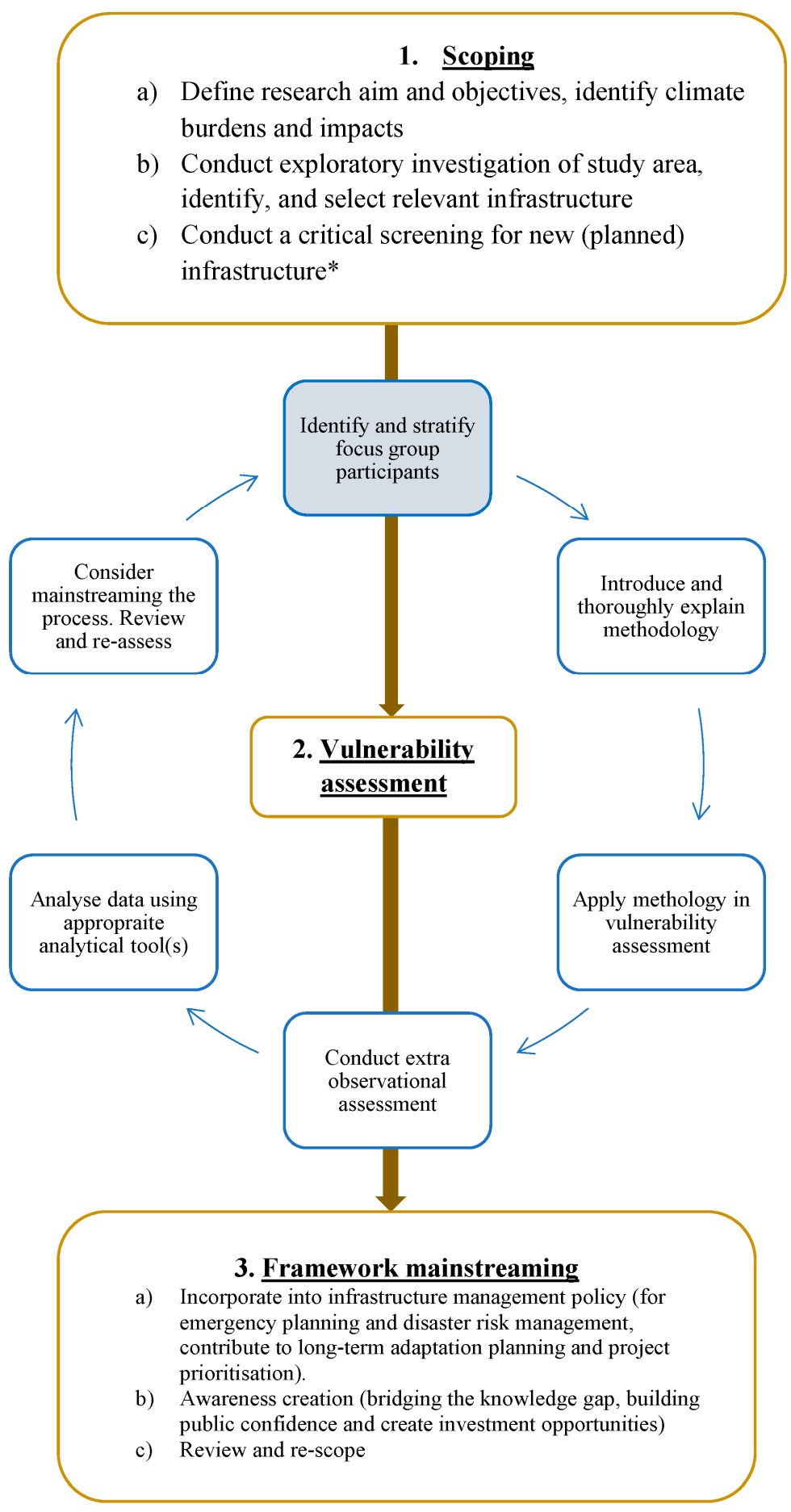

Figure 5. Overall schematic of multi-stakeholder framework for assessing the vulnerability of oil/gas infrastructure to climate change impact.

\section{Discussion}

Extreme weather events forced by climate change are impacting on critical infrastructures such as telecommunication, transport and energy systems globally. Depending on location, age, interdependency, sensitivity and exposure levels, these systems become increasingly vulnerable and at high risk of severe damages in the nearest future. Researchers have designed frameworks for vulnerability assessment and produce results that aid adaptation planning in various industries 
including energy. However, regional variances in environmental burdens and socioeconomic paradigms limit the application and transferability of external frameworks. In the Niger Delta context, the task of protecting oil/gas infrastructure from social and environmental impacts relies on a variety of stakeholders. Experts, government and local authorities are accountable stakeholders; hence the relevance of participatory framework approach for the vulnerability assessment in the context of the Niger Delta. This specific approach is insufficiently presented in existing literature $[14,16,27]$. Existing frameworks focus on the vulnerability assessment of only existing infrastructure, while this framework emphasises in the incorporation of new (planned) assets into the assessment process to determine their vulnerability from the start. Furthermore, the concept of vulnerability assessment for the Niger Delta oil and gas industry is relatively new and has become topical due to the increasing rates of floods, sea level rise and increasing temperature events. This framework has close the gap of inclusive assessment and scoping of vulnerable infrastructure to climate burdens. This framework could be used to conceptualise a methodology for evaluation of vulnerable assets in a hierarchical order for prioritised adaptation planning.

This paper presents a conceptual framework for assessment of critical oil/gas infrastructure in the Niger Delta case using a multi-stakeholder engagement approach. It diversifies the concept of scoping to include identification of existing and inclusion of new (planned) infrastructure into the assessment pathway to ensure that inbuilt adaptation mechanisms are incorporated at the build-up stage. In this study, the emphasis on planned infrastructure led to the identification of a central compressed processing and central processing facility $(\mathrm{CCP} / \mathrm{CPF})$ that lacks inbuilt adaptation mechanisms. The CCP/CPF is a joint venture gas monetisation infrastructure investment sited in an inundated area ( $4.5 \mathrm{~m}$ above sea level) and about $80 \mathrm{~m}$ from Atlantic shore with certain probabilities of being flooded by salt water overtopping the coast-line. Through application of the framework, it was discovered that the mix of salt water and increasing temperature have potential of causing corrosion effects. Conventional vulnerability assessment frameworks would have omitted this type of infrastructure, hence the exposure of newly commissioned facilities to climate impact. Scoping as indicated in this paper involves intensive review and field exploration to ensure that prevailing climate burdens and potential effects are considered in the long-term planning process. Unlike the conceptual framework of Fussel [34] that presents a generic scoping approach, this framework focuses on oil/gas assets though applicable in other sectors.

In addition to scoping, the study places iterative vulnerability assessment as a central step-connecting scoping with mainstreaming [14,27]. Assessment frameworks suggested by the Australian Capital Territory [14,27] mainly centre on vulnerability assessment with little emphasis on mainstreaming. This framework stresses on the mainstreaming of assessment and reduces the time required to complete each stage of investigation. It is essential to incorporate this conceptual framework into organisational asset management systems accompanied by a backup policy. In this study, mainstreaming provides a practical advantage for implementing the framework and a feedback mechanism for continual improvement of the research process.

The framework allows for integration of a suitable specific methodology an interdisciplinary research process. In this study, the analytic hierarchy process (AHP) was used to engage stakeholders in the Niger Delta to identify and prioritise shortlisted infrastructure in order of vulnerability. Decision-makers from four oil companies participated in the vulnerability assessment of critical infrastructure. Though details and results of the application of AHP are outside the scope of this paper, it provides insight into how stakeholders appreciate interdisciplinary interactions where every judgement is considered. This approach goes beyond to the frameworks presented by Moser and Ekstrom $[8,20,21]$ which are based on theories and analysis of academic principles.

A systematic application of this framework with relevant methodologies could aid the process of building critical infrastructure resilience in the Niger Delta. Vulnerability assessment of critical oil/gas assets to extreme climate disasters. These disasters include floods, extreme temperatures, storms and heavy downpours that requires the development of sustainable adaptation mechanisms that 
increases the resilience and resistance of relevant infrastructure. Resilient oil/gas systems in the Niger Delta region may translate directly to socio-economic growth, environmental protection and effective conservation of resources. For example, it can increase the capacity to minimise oil spills which often occur due to flood induced pipeline eruptions in the region. Availability of resilient systems with inbuilt adaptive capacities promotes investors' confidence in joint venture agreements and shared capacities, hence promoting trust and continual investment in the sector.

Nevertheless, there are some limitations associated with the chosen methodology in applying this framework in field investigations. These limitations relate to cultural issues in the Niger Delta oil/gas industry. There is a serious challenge in establishing contacts with industry stakeholders for participatory research. This is because decision makers in the industry operate on a tight schedule almost all year round. Secondly, the application of AHP questionnaire is time consuming and could be cumbersome with less experienced participants. To save time in the application of framework, Dinner et al. [21] developed none participatory theoretical indicators for vulnerability assessment of coastal systems. Other challenges include the social volatility of the region. Escalation of the crisis in the region may suddenly frustrate research timelines due increased security barriers and declaration of force majeure in the industry. Force majeure such as that which was declared in the Niger Delta during the 2012 flood [68] obstructs exploration and observational data collection in real time which may bring the research to a halt. Further challenges include bureaucratic bottlenecks, high ethical standards and perplexity of confidentiality agreements and various documentations as a prerequisite for accessing participants and operational sites. Contacts through informal channels could avoid this problem and still produce a valid outcome. To overcome these limitations, the research approach can incorporate a combination of modelling, developing a system of dynamic assessment strategies and using effective desk scoping that includes new infrastructure in the vulnerability assessment [20].

\section{Conclusions and Recommendation}

This paper presents a conceptual framework for a systematic vulnerability assessment of oil/gas infrastructure in the Niger Delta context. Study aim, objectives, prevailing climate burdens and infrastructure assessment were determined through scoping-field exploration and desk reviews. Selected infrastructures are clearly exposed to extreme climate induced conditions such as flood, storms and temperature in the region with the potential of causing damages. Emphasis is placed on the inclusion of new (planned) infrastructure in the assessment process to avoid the future cost and time wastage on routine assessments. The second segment of the framework is an iterated six-step systematic vulnerability assessment procedure that combines analytic hierarchy process (AHP) with stakeholder participation through focus groups and observational approaches for data collection. The Mi-AHP spreadsheet was used to analyse data that prioritised selected asset in merit order (most to the least vulnerable) in the study area. The framework is flexible and allows for the use of any suitable method in the vulnerability assessment depending on the research design. A brief of how AHP was applied is presented in this paper as a guide. Section three of framework emphasises the need for mainstreaming of this study into industrial management system and practice. It is believed that this framework is a commercial tool that policy makers could adopt for assets management with the aim of developing sustainable climate adaptation options for critical infrastructure. Vulnerability assessment is an opportunity to create institutional awareness and information dissemination, job creation and building investor/partnership confidence in joint venture operations. Mainstreaming also creates an opportunity for framework application monitoring, review, adjustments and re-scoping in the new assessment process.

The framework is recommended for interdisciplinary stakeholder engagement for assessment of established vulnerable energy infrastructure such as hydroelectric systems, National Integrated Power Plants (NIPP), thermal power stations and solar farms' in different regions. Other sectors such as transport, housing, telecommunication, agriculture, etc. could trial this framework using other 
MCDA tools such as analytic network process (ANP) and fuzzy AHP, in addition to other methods that encourage participatory investigation.

Acknowledgments: The first author is grateful to the Petroleum Technology Development Fund (PTDF), Nigeria; for financial support towards his doctoral study at the Institute of Energy and Sustainable Development (IESD), De Montfort University, Leicester; for making this publication.

Author Contributions: This paper is an outcome of a research framework conceived by Justin Udie as part of his doctoral research. Subhes Bhattacharyya and Leticia Ozawa-Meida are first and second supervisors who provided support and the primary edit of the work.

Conflicts of Interest: The authors declare no conflict of interest.

\section{References}

1. Adelekan, I.O. Vulnerability of poor urban coastal communities to flooding in Lagos, Nigeria. Environ. Urban. 2010, 22, 433-450. [CrossRef]

2. Adesola, O.A.; Adesodun, A.I.; Adekola, D.R. Impact of oil revenue on economic development in Nigeria (1981-2012). J. Soc. Dev. Sci. 2014, 5, 73-78.

3. Akinwale, A.A. The menace of inadequate infrastructure in Nigeria. Afr. J. Sci. Technol. Innov. Dev. 2010, 2, 207-228.

4. Hitz, S.; Smith, J. Estimating global impacts from climate change. Glob. Environ. Chang. 2004, 14, $201-218$. [CrossRef]

5. Avata. The Oil \& Gas Industry; Avata: Wheat Ridge, CO, USA, 2017; Available online: http:/ / avata.com/oilgass (accessed on 23 October 2017).

6. Ozor, N. Difficulties in adaptation to climate change by farmers in Enugu State, Nigeria. J. Agric. Ext. 2010, 14. [CrossRef]

7. Velarde, S.J.; Malhi, Y.; Moran, D.; Wright, J.; Hussain, S. Valuing the impacts of climate change on protected areas in Africa. Ecol. Econ. 2005, 53, 21-33. [CrossRef]

8. Moser, S.C.; Ekstrom, J.A. A framework to diagnose barriers to climate change adaptation. Proc. Natl. Acad. Sci. USA 2010, 107, 22026-22031. [CrossRef] [PubMed]

9. Vugrin, E.D.; Warren, D.E.; Ehlen, M.A.; Camphouse, R.C. A framework for assessing the resilience of infrastructure and economic systems. In Sustainable and Resilient Critical Infrastructure Systems; Springer: Berlin, Germany, 2010; pp. 77-116.

10. Nzeadibe, T.C.; Egbule, C.L.; Chukwuone, N.A.; Agwu, A.E.; Agu, V.C. Indigenous innovations for climate change adaptation in the Niger Delta region of Nigeria. Environ. Dev. Sustain. 2012, 14, 901-914. [CrossRef]

11. MacDonald, A.M.; Calow, R.C.; MacDonald, D.M.; Darling, W.G.; Dochartaigh, B.E. What impact will climate change have on rural groundwater supplies in Africa? Hydrol. Sci. J. 2009, 54, 690-703. [CrossRef]

12. Oels, A. Rendering climate change governable by risk: From probability to contingency. Geoforum 2013, 45, 17-29. [CrossRef]

13. Saaty, T.L. The seven pillars of the analytic hierarchy process. In Multiple Criteria Decision Making in the New Millennium; Springer: Berlin, Germany, 2001; pp. 15-37.

14. ACT Government, Chief Minister and Cabinet Office. Climate Change Vulnerability Assessment Framework for Infrastructures; Australian Capital Territory: Canberra, Australia, 2012.

15. Burch, S.; Robinson, J. A framework for explaining the links between capacity and action in response to global climate change. Clim. Policy 2007, 7, 304-316. [CrossRef]

16. Makino, K. An empirical research framework for the aesthetic appreciation of the urban environment. City Cult. Soc. 2017. [CrossRef]

17. Moss, R.H.; Edmonds, J.A.; Hibbard, K.A.; Manning, M.R.; Rose, S.K.; van Vuuren, D.P.; Carter, T.R.; Emori, S.; Kainuma, M.; Kram, T. The next generation of scenarios for climate change research and assessment. Nature 2010, 463, 747-756. [CrossRef] [PubMed]

18. Jones, R.N. An environmental risk assessment/management framework for climate change impact assessments. Nat. Hazards 2001, 23, 197-230. [CrossRef]

19. Christopher, C.W. Success by a thousand cuts: The use of environmental impact assessment in addressing climate change. Vt. J. Environ. Law 2007, 9, 549. [CrossRef] 
20. Tonmoy, F.N.; El-Zein, A. Vulnerability of infrastructure to sea level rise: A combined outranking and system-dynamics approach. In Proceedings of the 22nd Conference on European Safety and Reliability (ESREL-2013), Amsterdam, The Netherlands, 29 September-2 October 2013.

21. Denner, K.; Phillips, M.R.; Jenkins, R.E.; Thomas, T. A coastal vulnerability and environmental risk assessment of Loughor Estuary, South Wales. Ocean Coast. Manag. 2015, 116, 478-490. [CrossRef]

22. Oh, E.H.; Deshmukh, A.; Hastak, M. Vulnerability assessment of critical infrastructure, associated industries, and communities during extreme events. In Construction Research Congress 2010: Innovation for Reshaping Construction Practice; American Society of Civil Engineers: Reston, VA, USA, 2010; pp. 449-469.

23. Helm, D. The European framework for energy and climate policies. Energy Policy 2014, 64, 29-35. [CrossRef]

24. Rahil, A.; Gammon, R. Dispatchable hydrogen production at the forecourt for electricity demand shaping. Sustainability 2017, 9, 1785. [CrossRef]

25. Prato, T. Conceptual framework for assessment and management of ecosystem impacts of climate change. Ecol. Complex. 2008, 5, 329-338. [CrossRef]

26. Kalaugher, E.; Bornman, J.F.; Clark, A.; Beukes, P. An integrated biophysical and socio-economic framework for analysis of climate change adaptation strategies: The case of a New Zealand dairy farming system. Environ. Model. Softw. 2013, 39, 176-187. [CrossRef]

27. Federal Highway Administration. Climate Change and Extreme Weather Vulnerability Assessment Framework; USA Department of Transport: Washington, DC, USA, 2012.

28. Science Applications International Corporation (SAIC). Transportation Policy and Analysis Centre and 7990 Science Applications Court. In A Guide to Highway Vulnerability Assessment for Critical Asset Identification and Protection; Technique Reports 20-07/Task 151B; American Association of State Highway and Transportation Officials' Task Force: Vienna, VA, USA, 2002.

29. MacArthur, J.; Mote, P.; Ideker, J.; Figliozzi, M.; Lee, M. Climate Change Impact Assessment for Surface Transportation in the Pacific Northwest and Alaska; Transportation Research and Education Center (TREC): Portland, OR, USA, 2012.

30. Fuchs, S.; Heiss, K.; Hübl, J. Towards an empirical vulnerability function for use in debris flow risk assessment. Nat. Hazards Earth Syst. Sci. 2007, 7, 495-506. [CrossRef]

31. Ellison, A.M. An introduction to Bayesian inference for ecological research and environmental decision-making. Ecol. Appl. 1996, 6, 1036-1046. [CrossRef]

32. Goepel, K.D. Implementing the analytic hierarchy process as a standard method for multi-criteria decision making in corporate enterprises-A new AHP excel template with multiple inputs. In Proceedings of the 7th International Symposium on the Analytic Hierarchy Process, Bali, Indonesia, 7-9 August 2013; pp. 1-10.

33. Füssel, H.; Klein, R.J. Climate change vulnerability assessments: An evolution of conceptual thinking. Clim. Chang. 2006, 75, 301-329. [CrossRef]

34. Füssel, H. Vulnerability: A generally applicable conceptual framework for climate change research. Glob. Environ. Chang. 2007, 17, 155-167. [CrossRef]

35. Saaty, T.L. Decision making with the analytic hierarchy process. Int. J. Serv. Sci. 2008, 1, 83-98. [CrossRef]

36. Jagtap, H.P.; Bewoor, A.K. Use of analytic hierarchy process methodology for criticality analysis of thermal power plant equipments. Mater. Today Proc. 2017, 4, 1927-1936. [CrossRef]

37. Al-Harbi, K.M.A. Application of the AHP in project management. Int. J. Proj. Manag. 2001, 19, $19-27$. [CrossRef]

38. Thirumalaivasan, D.; Karmegam, M.; Venugopal, K. AHP-DRASTIC: Software for specific aquifer vulnerability assessment using DRASTIC model and GIS. Environ. Model. Softw. 2003, 18, 645-656. [CrossRef]

39. Ouma, Y.O.; Tateishi, R. Urban flood vulnerability and risk mapping using integrated multi-parametric AHP and GIS: Methodological overview and case study assessment. Water 2014, 6, 1515-1545. [CrossRef]

40. Arksey, H.; O'Malley, L. Scoping studies: Towards a methodological framework. Int. J. Soc. Res. Methodol. 2005, 8, 19-32. [CrossRef]

41. Schipper, L.; Pelling, M. Disaster risk, climate change and international development: Scope for, and challenges to, integration. Disasters 2006, 30, 19-38. [CrossRef] [PubMed]

42. Mitchell, J.K. The primacy of partnership: Scoping a new national disaster recovery policy. Ann. Am. Acad. Political Soc. Sci. 2006, 604, 228-255. [CrossRef] 
43. Burch, S. Transforming barriers into enablers of action on climate change: Insights from three municipal case studies in British Columbia, Canada. Glob. Environ. Chang. 2010, 20, 287-297. [CrossRef]

44. O’Brien, G.; O'Keefe, P.; Rose, J.; Wisner, B. Climate change and disaster management. Disasters 2006, 30, 64-80. [CrossRef] [PubMed]

45. Adejuwon, J.O. Rainfall seasonality in the Niger Delta Belt, Nigeria. J. Geogr. Reg. Plan. 2012, 5, 51.

46. Gersonius, B.; Ashley, R.; Pathirana, A.; Zevenbergen, C. Climate change uncertainty: Building flexibility into water and flood risk infrastructure. Clim. Chang. 2013, 116, 411-423. [CrossRef]

47. Yousefpour, R.; Jacobsen, J.B.; Thorsen, B.J.; Meilby, H.; Hanewinkel, M.; Oehler, K. A review of decision-making approaches to handle uncertainty and risk in adaptive forest management under climate change. Ann. For. Sci. 2012, 69, 1-15. [CrossRef]

48. Li, Q.; Liu, G.; Liu, X.; Li, X. Application of a health, safety, and environmental screening and ranking framework to the Shenhua CCS project. Int. J. Greenh. Gas Control 2013, 17, 504-514. [CrossRef]

49. Hiscock, K.; Tyler-Walters, H.; Jones, H. High Level Environmental Screening Study for Offshore Wind Farm Developments_Marine Habitats and Species Project; The Marine Biological Association: Plymouth, UK, 2002.

50. Payton, T.J. System and Method for Processing a Mixture of Hydrocarbon and CO2 Gas Produced from a Hydrocarbon Reservoir. U.S. Patent Application No. 7654320B2, 2 February 2010.

51. Karimi, A.; Abdi, M.A. Selective dehydration of high-pressure natural gas using supersonic nozzles. Chem. Eng. Process. 2009, 48, 560-568. [CrossRef]

52. Dew Point Control. JT Unit Skids. Dew Point Control, 20 March 2017. Available online: http: / / dewpointcontrol.com/pics/jtSkidModelB.jpg (Accessed on 23 November 2017).

53. Holdridge, L.R.; Grenke, W.C. Forest Environments in Tropical Life Zones: A Pilot Study; Pergamon Press: Oxford, NY, USA, 1971.

54. Van Teijlingen, E.R.; Hundley, V. The Importance of Pilot Studies. 2001. Available online: http:/ /aura.abdn. ac.uk/handle/2164/157 (accessed on 17 December 2017).

55. Kitzinger, J. Qualitative research. Introducing focus groups. Br. Med. J. 1995, 311, 299-302. [CrossRef]

56. Krueger, R.A.; Casey, M.A. Focus Groups: A Practical Guide for Applied Research; Sage Publications: Thousand Oaks, CA, USA, 2014.

57. Dong, Y.; Zhang, G.; Hong, W.; Xu, Y. Consensus models for AHP group decision making under row geometric mean prioritization method. Decis. Support Syst. 2010, 49, 281-289. [CrossRef]

58. Grove, S.J.; Fisk, R.P. Observational data collection methods for services marketing: An overview. J. Acad. Mark. Sci. 1992, 20, 217-224. [CrossRef]

59. Frischknecht, R.; Jungbluth, N.; Althaus, H.; Bauer, C.; Doka, G.; Dones, R.; Hischier, R.; Hellweg, S.; Humbert, S.; Köllner, T. Implementation of Life Cycle Impact Assessment Methods; Ecoinvent Report; Swiss Centre for Life Cycle Inventories: Dübendorf, Switzerland, 2007.

60. Dessai, S.; Hulme, M. Assessing the robustness of adaptation decisions to climate change uncertainties: A case study on water resources management in the east of England. Glob. Environ. Chang. 2007, 17, 59-72. [CrossRef]

61. Kloprogge, P.; der Sluijs, V.P.J. The inclusion of stakeholder knowledge and perspectives in integrated assessment of climate change. Clim. Chang. 2006, 75, 359-389. [CrossRef]

62. Rebitzer, G.; Ekvall, T.; Frischknecht, R.; Hunkeler, D.; Norris, G.; Rydberg, T.; Schmidt, W.-P.; Suh, S.; Weidema, B.P.; Pennington, D.W. Life cycle assessment: Part 1: Framework, goal and scope definition, inventory analysis, and applications. Environ. Int. 2004, 30, 701-720. [CrossRef] [PubMed]

63. Goepel, K.D. AHP Excel Template with Multiple Inputs. 2015. Available online: https://bpmsg.com/newahp-excel-template-with-multiple-inputs / (accessed on 28 November 2016).

64. Huq, S.; Reid, H.; Konate, M.; Rahman, A.; Sokona, Y.; Crick, F. Mainstreaming adaptation to climate change in least developed countries (LDCs). Clim. Policy 2004, 4, 25-43. [CrossRef]

65. Dawson, J.L.; John, G.; Oliver, K. 4.41-Management of Corrosion in the Oil and Gas Industry; Elsevier: Oxford, UK, 2010.

66. Arndt, C.; Chinowsky, P.; Strzepek, K.; Thurlow, J. Climate change, growth and infrastructure investment: The case of Mozambique. Rev. Dev. Econ. 2012, 16, 463-475. [CrossRef] 
67. Blyth, W.; Bradley, R.; Bunn, D.; Clarke, C.; Wilson, T.; Yang, M. Investment risks under uncertain climate change policy. Energy Policy 2007, 35, 5766-5773. [CrossRef]

68. Tami, A.G.; Moses, O. Flood vulnerability assessment of Niger Delta States relative to 2012 flood disaster in Nigeria. Am J. Environ. Prot. 2015, 3, 76-83.

(C) 2018 by the authors. Licensee MDPI, Basel, Switzerland. This article is an open access article distributed under the terms and conditions of the Creative Commons Attribution (CC BY) license (http://creativecommons.org/licenses/by/4.0/). 